\title{
EL ASOCIACIONISMO INMIGRATORIO ESPAÑOL EN URUGUAY EN LA MIRA DEL FRANQUISMO: ENTRE LA OPOSICIÓN Y EL DISCIPLINAMIENTO'
}

POR

CARLOS ZUBILLAGA

Universidad de la República (Uruguay)

\begin{abstract}
Se analiza la emergencia del asociacionismo español en Uruguay y la evolución de sus relaciones con el gobierno peninsular, particularmente en el contexto de la guerra civil y del régimen franquista. La información producida por la representación diplomática española en Montevideo se complementa con la prédica "hispanista» en libros y revistas editados en el seno de la colectividad inmigrada, tendente a la constitución de estructuras de disciplinamiento político e ideológico.
\end{abstract} glo $X X$.

Palabras Clave: inmigración, asociacionismo, Uruguay, franquismo, diplomacia, si-

\section{ANTECEDENTES DE ASOCIACIONISMO INMIGRATORIO EN URUGUAY}

Al promediar el siglo XIX culminó una dura contienda civil (la Guerra Grande), que enfrentó a los dos bandos políticos que habrían de constituir en el futuro los partidos tradicionales uruguayos. El país quedó económica y socialmente maltrecho; en el plano político resultó librado a un juego de confrontaciones que con frecuencia derivó hacia el campo de las armas, instaurándose un régimen democrático débil (por exclusión de la mayoría de la población en las prácticas electorales) y una institucionalidad frágil (por efecto del desplazamiento de los titulares del poder en circunstancias de excepcionalidad), que habría de mantenerse hasta el primer lustro del siglo XX. En este España.

1 Este artículo se inserta en el proyecto HUM2006-00765, financiado por el MEC de 
contexto se produjo la modernización de la economía, mediante la inserción del país en el comercio mundial en condición dependiente. Si bien para consagrar los cambios estructurales exigidos por esa internacionalización, hubo que apelar al ejército como brazo armado de un sistema oligárquico, realimentándose la debilidad de la democracia censitaria consagrada por la Constitución de 1830, ello no obstó para que Uruguay fuera percibido por los emigrantes europeos (españoles e italianos, fundamentalmente) como destino propicio. La inmigración masiva que se produjo a partir de la década de 1870 contribuyó, entonces, a rediseñar el modelo demográfico, acentuar las diferencias entre campo y ciudad, demandar reformas educativas y contribuir a la dilución de la matriz criolla en una identidad esencialmente plural.

La debilidad que los servicios públicos evidenciaron en la segunda mitad del siglo XIX estuvo en el origen del asociacionismo inmigratorio español. Cuando en 1853 se sentaron en Montevideo las bases de la Asociación Española $1 .{ }^{a}$ de Socorros Mutuos, que habría de expandirse en las décadas siguientes en el resto del país y «exportarse» como experiencia de organización mutual a otras naciones del continente americano, se dio inicio a una modalidad de atención de la salud que intentó sortear la insuficiencia de la Asistencia Pública Nacional. Pequeños comerciantes y asalariados en diversas ramas de actividad constituyeron el núcleo inicial de la Asociación, cubriendo las prestaciones que ésta ofreció un amplio espectro: atención médica, tratamiento curativo, medicamentos y pensión sucedánea del jornal perdido por enfermedad. Aunque en la década siguiente a su creación, la Asociación Española recurrió a la Legación de España en Montevideo, para gestionar ante el Ministerio de Relaciones Exteriores uruguayo su reconocimiento (al amparo de la Real Orden de 17 de marzo de 1859 por la que se había dispuesto que los representantes diplomáticos españoles extendieran su acción tutelar a las «colectividad[es] de españoles que se reun[i]e[ra]n para prestarse mutuamente apoyo y socorro»), la actividad de la institución evidenció autonomía respecto de la política peninsular e incrementó su perfil de colectivo inmigratorio pluriétnico (catalanes, gallegos, vasco-navarros, asturianos, andaluces) e interclasista (asalariados, comerciantes, artesanos, pequeños rentistas).

El asociacionismo inmigratorio español tuvo a partir de la década de 1870 un fuerte crecimiento $^{2}$, cumpliendo múltiples objetivos: recreativos, solida-

2 Surgieron el Casino Español (1877), el Club Español (1878), el Centro Gallego (1879), el Centre Català (1881), la Sociedad Euskara de Montevideo (1885), el Laurak Bat, el Hospital-Asilo Español (1886), el Rat Penat (1886), la filial montevideana de la Unión Hispano-Americana Valle Miñor (1905), el Centro Asturiano (1910), el Centro Euskaro (1911), el Centro Recreativo Pontevedrés (1917), la Casa de Galicia (1917), la Unión Hijos de Morgada- 
rios, culturales, asistenciales, o combinando en complejas estructuras de funcionamiento más de uno de esos fines. Fueron entidades creadas por inmigrantes, solventadas por los aportes económicos de sus afiliados (la autosustentabilidad fue su signo y, en consecuencia, su legitimación para opinar, tomar partido o incidir en aspectos relacionados con la sociedad y la política de su tierra de nacimiento). No todas esas entidades lograron sobrevivir en un contexto, como el de la sociedad receptora, que atravesó crisis económico-financieras, políticas y sociales de diversa intensidad, hasta consagrar en la tercera década del siglo XX una estabilidad democrática y económica, que sufriría sin embargo embates disruptivos en 1933 (golpe de Estado encabezado por el Presidente Gabriel Terra) y una experiencia de dictadura militar entre 1973 y 1984 (en el marco de la doctrina de la seguridad nacional) 3 .

La emergencia y el mantenimiento del asociacionismo inmigratorio español en Uruguay, resultaron condicionados por el incremento o el deterioro de los saldos migratorios, debidos a las condiciones socioeconómicas en las sociedades de origen o de arribada, así como a las políticas restrictivas en materia demográfica (incluidos algunos atisbos de xenofobia encubierta, que se expresaron en la figura del inmigrante de rechazo consagrada por la legislación uruguaya al promediar la década de 1930)4.

En la medida que la mayor parte de la inmigración española reconocía causalidad económica, la actitud del colectivo ante la situación política peninsular fue de escaso involucramiento, lo que no obstó para que en ella se reflejaran tendencias encontradas, sobre todo en oportunidad de cambios operados en los centros de poder o de explosiones sociales (la Restauración, la Semana Trágica, la dictadura primorriverista, la instauración de la República). En tal sentido, la relación del asociacionismo español con la representación diplomática española en Montevideo fue ambigua: protocolar en la mayoría de los casos, no resultó apreciada como imprescindible por las dirigencias de las asociaciones para llevar adelante los planes institucionales. Las asociaciones de perfil españolizante y finalidad representativa de la élite inmigratoria, prestaron más atención a la dimensión protocolar de los vínculos con la Legación de España (apreciados como generadores de prestigio ante la sociedad de arribada); de allí, también, que los sectores populares de la colectividad, en particular los asalariados, tuvieran una actitud de desconfianza, cuando no de denuncia, respecto a la inacción de los diplomáticos españoles a la hora de defender los de-

nes (1918), el Casal Català (1926), entre otras, para sólo señalar las que mayor gravitación ejercieron en su época o se han mantenido hasta el presente.

3 Zubillaga, 1993

4 Zubillaga, 1998. 
rechos conculcados de sus coterráneos menos favorecidos ${ }^{5}$. Por su parte, las asociaciones de perfil étnico (en especial, las correspondientes a Galicia, el País Vasco o Cataluña), en la medida que su denominación no fuera una simple referencia toponímica, sino que resultara funcional a las propuestas regionalistas, autonomistas o nacionalistas, confirieron escasa atención a sus relaciones con la Legación de España y, por lo general, recibieron de ésta un trato prescindente. Puede decirse que no hubo una estrategia definida en la política exterior española para evaluar el potencial del asociacionismo inmigratorio en América, y que el personal diplomático de vieja escuela «sufrió» la vinculación con esos colectivos, como una obligación más bien ingrata de su cargo, presidida por la desconfianza cuando no por el rechazo social a las «clases bajas» que componían la masa de las instituciones ${ }^{6}$. Para el caso uruguayo esto fue así - en términos generales-, por lo menos hasta el estallido de la Guerra Civil en la península. Hubo, a partir del alzamiento una división que instauró en el seno de la inmigración española en el país, severas confrontaciones mantenidas por casi tres décadas.

\section{EL DESAFÍO IMPUESTO POR LA GUERRA CIVIL}

Si bien la mayor parte de las asociaciones de inmigrantes españoles tenía vedado por sus Estatutos o Reglamentos incursionar en temas políticos, y las direcciones de algunas de ellas apelaron a ese impedimento para prolongar una

5 Un episodio representativo de esta actitud tuvo lugar en diciembre de 1901, con motivo de la huelga que mantenían los peones de barracas españoles contra sus patronos: los asalariados solicitaron a las autoridades diplomáticas de su país (ministro y cónsul) que les aseguraran las garantías personales, ya que se veían «amenazados de muerte» y «faltos de libertad», porque la policía entraba en sus «domicilios sin orden de ninguna autoridad judicial» y los sacaba «maniatados» para obligarlos a trabajar por el jornal que a sus «amos se les antojaba». La negativa del representante diplomático a tomar cartas en el asunto motivó la crítica de «La España» (periódico liberal editado en Montevideo), que se refirió a «cacerías varsovianas contra los huelguistas» y a «tamaños ultrajes a súbditos de España» que era preciso reparar (La España, Montevideo, 9-12-1901).

${ }^{6}$ En agosto de 1938 el Agente del Estado español en Montevideo, el falangista Rafael Soriano, retomaba la maniquea catalogación de sus coterráneos, en términos inequívocos: «En forma categórica, se puede afirmar que las personas de nuestra colonia que por su trabajo han conseguido una independencia están a nuestro lado. En contra, todos aquellos que fracasaron y que ahora se unen al comunismo local, que los emplea en provecho propio, haciéndolos desfilar en cuantas manifestaciones efectúan y asistir a cuantos mítines organizan». Anexo al despacho . $^{\circ} 162$ de la Representación del Estado Español en el Uruguay. Montevideo, 29 de agosto de 1938, f. 17, Archivo del Ministerio de Asuntos Exteriores (AMAE), R 1007, Exp. 3. 
indefinición o neutralidad (que, en buen romance, no se distinguía de la estrategia de postergar definiciones hasta que la guerra concluyera y fuera nítido el campo triunfador), la pasión que ganó a la masa de afiliados y el proselitismo de militantes ideológicamente jugados, forzaron en no pocos casos que las instituciones se decantaran en solidaridades precisas. Principalmente, en apoyo a la causa republicana (así lo hicieron, en diversos momentos de la guerra, y fuera del obvio alineamiento del Círculo Republicano Español, la Asociación Española 1. ${ }^{a}$ de Socorros Mutuos, la Casa de Galicia, el Centro Asturiano, el Casal Català, el Centro Euskaro Español, y la Irmandade Galeguista); en tanto expresaron en diversos grados su adhesión al Movimiento, entidades que nucleaban menor número de asociados (el Centro Gallego, el Club Español) o eran reducto económico de la élite inmigratoria (la Cámara Española de Comercio $^{7}$ ) y de sus estrategias de acción en la sociedad de arribada (la Institución Cultural Española de Montevideo, el Hospital-Sanatorio Español).

El severo fraccionamiento que la Guerra Civil produjo en el seno del colectivo inmigrado español fue uno de los motivos de preocupación permanente de los diplomáticos franquistas acreditados en Montevideo ${ }^{8}$ : sus despachos hicieron frecuentemente una peculiar lectura de la realidad, dando a entender que la parte «sana y valiosa» de la colonia se manifestaba afecta a la Causa Nacional y que sólo «los fracasados que [eran] muchos y aparenta[ba]n ser

7 Prueba de que algunos elementos económicamente exitosos de la inmigración española en Uruguay mantuvieron su fidelidad a la República, lo ofreció el hecho de que decantada a favor del alzamiento la Cámara Española de Comercio, se fundó en julio de 1937 —a impulsos del Círculo Republicano Español- una Cámara Oficial de Comercio Española, que intentó promover el intercambio comercial entre Uruguay y los territorios leales al Gobierno de la República. En el Archivo del Centro Republicano Español [ACRE] de Montevideo, custodiado en la Facultad de Humanidades y Ciencias de la Educación, de la Universidad estatal, se conserva la documentación de esta Cámara y la de su continuadora — entre 1944 y 1967- la Cámara Española Republicana de Intercambio Comercial Hispano Uruguayo, de actividad más testimonial.

${ }^{8}$ Es preciso tener presente que en septiembre de 1936 Uruguay suspendió sus relaciones diplomáticas con el gobierno republicano, con motivo de la muerte de dos hermanas del vicecónsul uruguayo en Madrid a manos de milicianos. Si bien la Junta de Burgos mantuvo como agente oficioso al antiguo encargado de Negocios de la Legación, Rafael Soriano, éste recién fue reconocido como representante de la España Nacional en diciembre de 1937, oportunidad en la que el gobierno uruguayo acreditó como agente en Burgos al coronel Juan Pedro Ribas, militar de talante conservador. El reconocimiento de jure del gobierno franquista recién tendría lugar en febrero de 1939, ocasión en la que Soriano asumió funciones de encargado de Negocios. No obstante, al alinearse Uruguay — al término de la Guerra Mundial — en la política sancionatoria de las Naciones Unidas, sólo mantuvo un encargado de Negocios en Madrid, persistiendo una situación ambigua hasta 1952, cuando finalmente se regularizaron las relaciones entre ambos países con la acreditación de representantes con rango de ministros. 
más por estar unidos a los elementos perniciosos del país» adoptaban una actitud contraria al Movimiento, pero agregando que todos los inmigrantes que «por tibieza o por miedo» no hacían acto de presencia en las filas nacionalistas se inclinaban «más bien hacia [la] Causa»" ${ }^{9}$. Conscientes de las debilidades operativas (y de la resistencia generalizada en el ambiente uruguayo a la proclamada vocación «imperial» del alzamiento), el agente Soriano creó en octubre de 1936 la Unión Nacional Española (integrada por inmigrantes españoles y por uruguayos simpatizantes del Gobierno de Burgos) con la finalidad de recaudar fondos, que se remitieron en forma de ropa, medicamentos y «efectos» para el «Glorioso Ejército» comandado por Franco. Coetáneamente, se constituyó en Montevideo la sección uruguaya de la Falange Española Tradicionalista y de las JONS, que agrupó unos cientos de afiliados (asistentes al plato único), y fue el espacio declamatorio de algunos comerciantes devenidos en propagandistas ideológicos y el canal operativo de un reducido número de militantes (de uniforme, saludos y gritos; ocasionalmente armados con dosis de aceite de ricino para asegurar la disciplina, cuando no partícipes como provocadores en mítines republicanos).

El momento político ${ }^{10}$ ofrecía, en la visión simplista de los agentes franquistas, posibilidades muy favorables a la Causa nacional, por lo que sin ad-

9 Anexo al despacho ${ }^{\circ}{ }^{162}$ de la Representación del Estado Español en el Uruguay. Montevideo, 29 de agosto de 1938, AMAE, R 1007, Exp. 3. El agente Soriano estimaba en 7.000 los «rojos activos de la colonia» y en 5.000 «los nacionalistas», sobre un total de 50.000 españoles en Uruguay. Si bien las cifras reconocían la superioridad de los republicanos, sugerían un cierto equilibrio, que en manera alguna se correspondía con la realidad. Las entidades favorables al franquismo nunca superaron (en conjunto) los dos mil afiliados, y ni siquiera todos ellos podían ser tildados de «afectos a la Causa», pues no pocos dieron batalla al interior de las entidades, en ocasiones con buen resultado para inhibir compromisos irreversibles de adhesión al Régimen.

10 En marzo de 1933 el Presidente de la República, Gabriel Terra, dio un golpe de Estado, disolviendo el Parlamento e instaurando un régimen de facto, con desconocimiento de las libertades públicas y marginamiento de la oposición democrática. Fue este régimen el que interrumpió las relaciones diplomáticas con la República Española y alentó un acercamiento a la Junta de Burgos. La oposición antiterrista, en la que confluyeron sectores de los partidos políticos tradicionales (el batllismo, el nacionalismo independiente) y los denominados «partidos de ideas» (Unión Cívica, de inspiración democratacristiana; Partido Socialista; Partido Comunista), así como el movimiento sindical y el estudiantado universitario, mantuvo un cuestionamiento permanente del régimen, incluyendo una frustránea experiencia revolucionaria (en enero de 1935), sangrientamente reprimida. La proclividad de Terra y sus aliados políticos ante los regímenes totalitarios de derecha en Europa fue notoria, por lo que la oposición trabó fuertes vínculos con los inmigrantes antifascistas, antinazis y antifalangistas. Los alineamientos políticos ante la situación local se reflejaron entonces, fluidamente, en las solidaridades y los rechazos en la escena internacional. 
vertir lo errado de sus presunciones, dieron aquellos en creer (y sobre todo, en hacer creer a sus superiores en la Península) que la hegemonía conservadora en el gobierno uruguayo se mantendría sin solución de continuidad y abonaba el terreno de una expansión organizativa vaciada en el molde totalitario del régimen. De allí la propuesta que el secretario nacional de FET y de las JONS, Joaquín Rodríguez de Gortázar, formulara en julio de 1939 al jefe regional en Uruguay, José Luis Ruano, para que promoviera la fundación de un «Hogar Español» en Montevideo, cuyas bases estatutarias le remitió. Se trataba de dar cobertura a las estructuras de Falange, alineando a la colectividad inmigrada (en cuyo seno se suponían superados los temores o titubeos de la mayoría, dado el resultado inequívoco de la Guerra Civil). La consigna era que la masa social de FET y de las JONS se «inscribiera automáticamente como socios» de la nueva entidad, abandonando «el uso de uniformes, camisas azules, boinas y distintivos», pero teniendo claro que «toda fórmula de carácter democrático que pu[dieran] tener los Estatutos definitivos de la sociedad, sólo ser[í]a utilizada desde el punto de vista legal», porque la nueva entidad jurídica «se regir[í]a en lo fundamental, por la manera de ser nacional sindicalista de[1] Movimiento». De tal forma que el presidente de la institución sería en realidad el jefe provincial de FET y de las JONS, sólo «aparentemente designado por votación» ${ }^{11}$.

\section{EL FRACASO DE LA ESTRATEGIA DE COOPTACIÓN}

El inicio de la Guerra Mundial provocó un realineamiento de la política exterior uruguaya, reflejando el compromiso del Presidente Baldomir (sucesor de Terra) con la redemocratización del país: la tradicional vinculación con Gran Bretaña y Francia volvió a gravitar en el diseño de las estrategias diplomáticas. Por otra parte, la opinión pública se decantó mayoritariamente por la causa aliada, convirtiendo su movilización en tal sentido en una modalidad explícita de rechazo a los totalitarismos (lo que era pasible de una lectura más local: de oposición al autoritarismo conservador instaurado a partir del golpe de Estado de 1933). El clima se tornó francamente hostil al régimen franquista, llevando a la representación diplomática española a intentar diversas formas de cooptar el apoyo del asociacionismo inmigratorio para legitimarse como vocero de la colonia. Se pusieron en marcha, entonces, proyectos en cierto

11 Nota del Secretario Nacional Joaquín Rodríguez de Gortázar al Jefe Regional de FET $y$ de las JONS. San Sebastián, 12-7-1939, Archivo General de la Administración (AGA). Alcalá de Henares, 51/29040. 
modo incompatibles y que reflejaron escaso conocimiento de la realidad; de allí que resultaran inviables a corto plazo y terminaran por desnudar el desdén que en el fondo sentían, las estructuras del Movimiento y la diplomacia peninsular, por las indóciles masas de emigrantes.

El primer proyecto fue el de crear, de acuerdo con las instrucciones recibidas del Ministerio de Organización y Acción Sindical, un Patronato de Españoles, bajo la presidencia del encargado de Negocios, la vicepresidencia del segundo secretario de la Legación y la vocalía nata del jefe provincial de Falange. El núcleo de vocales lo completaban cinco «de libre elección» (en realidad cooptados por el encargado de Negocios, entre adherentes explícitos al Movimiento) y los representantes de las asociaciones reclutadas (las ya aludidas entidades que canalizaban el accionar de la elite inmigratoria, con escaso peso numérico y en ciertos casos, exclusivo carácter económico: Club Español, Cámara Española de Comercio, Industria y Navegación, Centro Gallego, Institución Cultural Española, Hospital Sanatorio Español, Banco Español del Uruguay; y dos entidades ad hoc, la Asociación Española de la Virgen del Pilar ${ }^{12}$ y la Casa de Asturias ${ }^{13}$ ). Los fines del Patronato ${ }^{14}$, enunciados en el acto de su instalación (el $1 .^{\circ}$ de febrero de 1940), eran un intento por atraer a la masa de inmigrantes con promesas (incumplibles, por otra parte) de beneficios sociales («protección económica y social, para instituir la obra de homenaje a la vejez, bolsas de trabajo, mutualidades obreras subvencionadas, defensa jurídica de los españoles para el sostenimiento de sus derechos en cuestiones de trabajo, repatriaciones y prestación de auxilio»). También se proponía una acción cultural «para la creación y sostenimiento de escuelas españolas, con preferencia elementales y nocturnas» (en desconocimiento de la enseñanza primaria gratuita y nocturna para adultos, existente en Uruguay desde $1903^{15}$ ), y una labor de asistencia sanitaria («creación y

12 Con apenas una veintena de adherentes, esta institución pretendió influir en el laicado católico uruguayo, invocando para el alzamiento la caracterización de cruzada. Su principal dirigente fue el doctor José María del Rey, estrecho colaborador de la representación diplomática franquista, y director del periódico El Pilar, financiado con recursos del Ministerio de Asuntos Exteriores.

13 Fundada en 1939 por un núcleo de asociados al Centro Asturiano (creado en Montevideo en 1910), discrepantes con la adhesión que este último había brindado al régimen republicano.

14 Borrador de la convocatoria cursada a las instituciones españolas para asistir al acto de instalación del Patronato de Españoles [Sin fecha, aunque seguramente de enero de 1940], AGA, 54/10080.

15 Durante las administraciones de los Presidentes José Batlle y Ordóñez (1903-1907) y Claudio Williman (1907-1911) se pusieron en funcionamiento cursos de enseñanza primaria para adultos (hombres y mujeres), primero en Montevideo y luego en todos los Departamentos 
sostenimiento, o impulsión y mayor arraigo, si ya estuviesen creados, de hospitales y dispensarios, auxilios a la maternidad, consultas médicas y cuanto pueda contribuir a defender la salud y la vida de los españoles en el Uruguay»). En este último rubro, se ignoraba la tradición del mutualismo médico inaugurado por los inmigrantes españoles en 1853 (con la creación de la Asociación Española

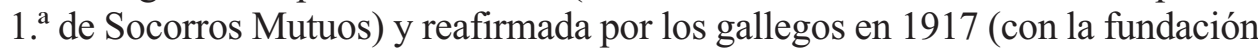
de la Casa de Galicia), que extendía por entonces los beneficios de su cobertura en salud a más de 40.000 afiliados (en su mayoría, primera y segunda generación de inmigrantes).

En el despacho en que dio cuenta de la instalación del Patronato, el encargado de Negocios, Francisco José del Castillo, aludió a los objetivos reales del emprendimiento: contrarrestar la propaganda «roja» de las «entidades que, desde la guerra, observa[ba]n una actitud hostil» hacia el régimen, y lograr «que desapare[cier]an las divisiones que [...] separa[ba]n [a la] colectividad y ces[ara] la campaña antiespañola $[\text { sic] }\rangle^{16}$. La labor realizada por el Patronato no incursionó en momento alguno por los cauces de sus formales finalidades, sino por los entresijos de la confrontación con las entidades antifranquistas del colectivo inmigrante o de la sociedad uruguaya. De hecho, en la segunda reunión del Patronato, el encargado de Negocios planteó sin eufemismos que la institución carecía de autonomía y estaba sujeta a la voluntad política de la legación. Abordó el problema planteado por las gestiones que se realizaban cerca del gobierno uruguayo para facilitar el ingreso de un cierto número de refugiados republicanos procedentes de Francia, diciendo ${ }^{17}: \ll[\ldots]$ sin entrar por el momento en el análisis del problema de los refugiados, [...] deb[o] prevenirles que sólo el Patronato tiene personalidad para realizar cualquier clase de gestiones que pu[edan] afectar a la Colonia española, como lo sería [...] la susodicha acción de las agrupaciones rojas, con manifiestos fines políticos, [que] no [puede] ser secundada por ninguna de las que integra[n] el Patronato» ${ }^{18}$.

El vigor de la campaña antifranquista en el seno de la sociedad uruguaya se incrementó, sobre todo a partir de la convergencia política entre la oposición y

del país. Coetánea del gran flujo inmigratorio, la medida gubernamental buscaba — en palabras de Williman - «dar nociones de lectura, escritura y aritmética» a las masas asalariadas.

16 Del Encargado de Negocios Francisco José del Castillo al Ministro de Asuntos Exteriores. Montevideo, 1-2-1940, AGA, 54/10080.

17 Del Encargado de Negocios Francisco José del Castillo al Ministro de Asuntos Exteriores. Montevideo, 27-2-1940, AGA, 54/10082.

18 En realidad, la imposición de conducta dictada por el diplomático obedecía a que dos de las entidades adheridas al Patronato, habían enviado representantes a la convocatoria realizada por el «Comité de ayuda a los refugiados españoles», lo que resultaba a todas luces disfuncional con los objetivos de la organización recién creada por la legación. 
el Presidente Baldomir, que daría a partir de febrero de 1942 un fuerte protagonismo a los partidos tradicionales uruguayos que habían expresado su solidaridad con la República Española (batllismo y nacionalismo independiente) y a los «partidos de ideas» (Unión Cívica, Partido Socialista y Partido Comunista). La entrada de la Unión Soviética y de los Estados Unidos en la guerra alentó en Uruguay un vigoroso clima aliadófilo, traducido en incisiva prédica periodística y capacidad de movilización multitudinaria. El Patronato de Españoles (que había servido de modelo para la creación en Montevideo de un «Directorio Colonial Italiano» auspiciado y orientado por la legación fascista), hubo de retraerse en sus pretensiones (y de hecho dejó de actuar ${ }^{19}$ ) a partir de la sanción en junio de 1940 de la Ley N. ${ }^{\circ} 9936$ (de asociaciones ilícitas ${ }^{20}$ ), por la que el gobierno uruguayo quedó habilitado para disolver por decreto aquellas instituciones que difundieran ideas contrarias a la forma de gobierno democrático-republicana, y las de carácter político o social (con excepción de las de naturaleza religiosa) que en su organización, funcionamiento, directrices, finalidades o provisión de recursos, estuvieran vinculadas a la voluntad de una persona o de un poder extranjero, o de cualquier entidad extraña al país, en vez de estarlo a la de sus asociados.

Ocluido el cauce del Patronato y autoclausurada, por los mismos motivos, la organización local de Falange ${ }^{21}$, la representación diplomática franquista buscó una alternativa institucional para mantener su incidencia en el seno del colectivo inmigrante. Se creó, entonces, Fundación Española (cuyos estatutos se encuadraron en las normas jurídicas uruguayas, aunque con propósito nada sutil se apeló a una denominación que dejó incambiada la sigla FE) a la que

19 A la vista de la disolución del Directorio Colonial Italiano, dispuesta por el gobierno uruguayo el 3 de febrero de 1942, en aplicación de las normas de la ley de asociaciones ilícitas, y poniendo «las barbas en remojo», el ministro de España marqués de los Arcos, resolvió obrar «con la mayor cautela en todo lo relacionado al funcionamiento» del Patronato, y mantener el libro de actas del mismo «depositado en los archivos de [la] Representación». Del Ministro de España Marqués de los Arcos al Ministro de Asuntos Exteriores. Montevideo, 5-2-1942, AGA, 54/10080.

20 Registro Nacional de Leyes y Decretos de la República Oriental del Uruguay. Año 1940, 1941: 365 y ss.

21 En acuerdo adoptado por las jerarquías locales y el encargado de Negocios de España en Montevideo, quienes evaluaron que «no quedaba ninguna posibilidad de que pudiese continuar existiendo en su forma original la organización de Falange» en el país, se clausuró el local de la misma en la primera semana de julio de 1940, antes de la entrada en vigor de la ley de asociaciones ilícitas (a la que, pudorosamente, el funcionario diplomático en comunicación a sus superiores, rebautizara «Ley sobre disolución de asociaciones políticas»). Del Encargado de Negocios Francisco José del Castillo al Ministro de Asuntos Exteriores. Montevideo, 13-7-1940, AMAE, R 1569, Exp. 14. 
concurrieron como afiliados los que lo habían sido de Falange, y en la que para «salvar en lo posible los inconvenientes y riesgos de la forma electiva de los cargos» se fijó la presidencia efectiva permanente (siempre que quisiera hacer uso de tal potestad) en el representante diplomático de España ${ }^{22}$. La instalación del nuevo organismo social tuvo lugar el 13 de julio de 1940, en acto que presidió el encargado de Negocios y al que asistió el personal de la legación y diecinueve personas (entre las cuales la jerarquía de Falange en Uruguay); los propósitos enunciados resultaron menos ambiciosos que los del Patronato de Españoles, aunque igualmente retóricos («Realizar todas las actividades sociales, culturales, benéficas y deportivas que, por sí misma o en colaboración con otras agrupaciones españolas, pueda llevar a cabo dentro de las normas o limitaciones previstas por las leyes uruguayas; colaborar en aquellas obras de carácter hispánico y uruguayo que tiendan a estrechar la unión entre el Uruguay y España, mediante el conocimiento cada vez más hondo de las virtudes y valores recíprocos») ${ }^{23}$. Fracasado el modelo del Patronato, por incapacidad para obtener ancha base social a partir de la adhesión de asociaciones de inmigrantes diversas de las «adictas a la Causa», la representación franquista optó por preservar un espacio para el actuar de Falange, difuminando sus objetivos tras una huera invocación al hispanoamericanismo y a la fraternidad entre sus asociados (para conseguir la cual se apelaría a «los más nobles recursos»), y conformándose con una masa de asociados que no superó las trescientas personas.

Sin embargo, a pesar de la «prudencia» en la exposición pública de sus actividades (clases de Historia Patria española, enseñanza de bailes regionales, conferencias de carácter cultural y otras «enaltecedoras de la obra de resurgimiento en España»), y ciertos movimientos tendentes a congraciarse con el sistema político local ${ }^{24}$, la afiliación en masa de los antiguos integrantes de $\mathrm{Fa}$ lange no pasó desapercibida para la opinión pública montevideana. Los diarios El País y El Plata (que respondían al nacionalismo independiente) iniciaron una campaña de prensa denunciando la peculiaridad de los Estatutos de la Fundación, que conferían amplias facultades de orientación y dirección al ministro de España acreditado ante el gobierno uruguayo, violando así las nor-

22 Idem.

23 Del Ministro de España Marqués de los Arcos al Ministro de Asuntos Exteriores. Montevideo, 18-11-1940, AGA, 54/10079.

24 Al inaugurar el 17 de noviembre de 1940 su sede (en un local de la Ciudad Vieja cuya segunda planta la ocupaba la «Sección Femenina» [de Falange] encubierta bajo el rótulo de «Comisión de Damas» de la Fundación Española), se procedió a la bendición del escudo y de las banderas española y uruguaya, aceptando amadrinar la española la esposa del intendente de Montevideo, en tanto la esposa del ministro de España hacía lo propio con la uruguaya. 
mas de la ley de asociaciones ilícitas. El marqués de los Arcos dio cuenta a su superior de tales contratiempos: «[...] la prensa y elementos políticos que nos son adversos no han cejado en su empeño de atacar a la Fundación alegando ser Falange disfrazada y pidiendo su disolución, como asociación ilícita. [...] Como en toda la campaña contra colegios alemanes e italianos o entidades sospechosas de simpatías con los países del eje o totalitarios, se ha venido empleando el argumento de que al estar sujetas a una persona o poder extranjero las directrices que marcara ésta eran atentatorias a la democracia o instituciones fundamentales del país $[. . .]^{25}$. Tomó cartas en el asunto la Comisión Especial del Ministerio del Interior, encargada de la investigación constante de las agrupaciones sospechosas de ilicitud (a la luz de las disposiciones de la ley de 1940), y aunque la Fundación obtuvo un pronunciamiento favorable del fiscal de Gobierno en el sentido de que «es siempre la voluntad de sus asociados - asociados dirigidos y asociados dirigentes - la que decidirá de sus actividades y funcionamiento, y no está así vinculada a la voluntad de una persona extranjera, que la imponga contra la voluntad de los socios», el poder ejecutivo decretó el 28 de enero de 1942 la disolución de la entidad ${ }^{26}$, procediendo la fuerza policial a incautar el libro de actas y la «escasa documentación obrante en la sede», por cuanto la documentación sustancial y el fichero de Falange (que había servido para configurar el padrón social) se hallaban depositados en la legación.

\section{INTERMEDIO AZAROSO}

Influido por la política panamericana del Departamento de Estado, Uruguay tuvo participación activa en el diseño de la solidaridad continental contra el peligro expansivo de los totalitarismos articulados en el Eje. Fruto de esa estrategia fue la recomendación formulada por la Tercera Reunión de Cancilleres, celebrada en Río de Janeiro, por la que se instó a los países americanos a

25 Del Ministro de España Marqués de los Arcos al Ministro de Asuntos Exteriores. Montevideo, 3-6-1941, AGA, 54/10078.

${ }^{26}$ El marqués de los Arcos cursó ese mismo día un telegrama cifrado al Ministerio de Asuntos Exteriores, dando cuenta de que el poder ejecutivo había considerado a la Fundación Española «comprendida en [...] la Ley de Asociaciones Ilícitas [...] como vinculada a persona o poder extranjero y constituida con finalidad de acción política en el exterior». Terminaba su comunicación señalando: «Esperada esta medida hace días a pesar gestiones verbales realizadas por intensa campaña prensa y medidas adoptadas contra toda actividad y propaganda totalitaria». Del Ministro de España Marqués de los Arcos al Ministro de Asuntos Exteriores. Montevideo, 28-1-1943 [telegrama cifrado], AGA, 54/10078. 
romper relaciones con Japón, Alemania e Italia; actitud que el gobierno uruguayo concretó el 25 de enero de 1942, ampliando sus efectos al declarar una semana más tarde «no beligerantes» las naves de Gran Bretaña y demás países extracontinentales que defendían los intereses aliados. La situación para las personas, asociaciones y empresas vinculadas al nazi-fascismo o sospechadas de simpatía hacia el Eje (entre las que se incluían, obviamente, las «adictas» a la España franquista), se tornó difícil: circularon listas negras que intentaban bloquear el potencial económico de las actividades «antinacionales» y se incrementó el repudio público de las concepciones racistas así como de los planes de dominio y reparto territorial con que los gobiernos de Tokio, Berlín y Roma habían alterado el mapa mundial. No resultó ajena a este repudio la política franquista de negociación de la entrada de España en la guerra con el precio de una satisfacción (aunque periférica) de su «vocación de Imperio»; sin importar lo fallido de este intento, la alineación de Madrid con la política del Eje resultó ratificada al encargarse España de los asuntos italianos y alemanes en Uruguay, una vez rotas las relaciones diplomáticas con los regímenes fascista y nazi.

La legislación uruguaya previsora de la infiltración totalitaria alcanzó hacia fines de 1942 su nivel máximo, mediante un decreto-ley que estableció como delito la promoción, constitución, organización o dirección, aunque fuera «bajo falso nombre o en forma simulada», de «asociaciones, secciones, entes o instituciones contrarias al régimen democrático republicano establecido por la Constitución de la República» ${ }^{27}$. La posibilidad de un nuevo emprendimiento simulatorio como el de Fundación Española estaba definitivamente ocluida.

La legación española hubo de adaptarse a la situación, manteniendo relaciones protocolares con el asociacionismo inmigratorio «adicto» y alentando en la élite decantada hacia el Movimiento un espíritu «alerta», que identificara las críticas al franquismo con «traición a la patria». El ambiente no daba para más, sobre todo a partir del momento en que Uruguay participó activamente en la Conferencia de San Francisco y suscribió la Carta de las Naciones Unidas. La política exterior uruguaya se caracterizó por acompañar las sanciones con las que el organismo internacional deslegitimó el origen del régimen franquista e inhibió el ingreso de España al sistema. De allí que los ministros españoles acreditados en Montevideo debieron prestar más atención a las gestiones reservadas ante agentes políticos locales «benévolos»o a los intentos de con-

27 El decreto-ley de 19 de noviembre de 1942 sancionó, asimismo, con pena de prisión, la mera participación en tales asociaciones. Registro Nacional de Leyes y Decretos de la República Oriental del Uruguay. Año 1942, 1943: 1369-1370. 
vencer a la Cancillería uruguaya de que España no había sido solidaria con el Eje sino enemiga del comunismo, antes que abocarse a una labor de «domesticación» de los inmigrantes. En todo caso, respaldaron la acción provocadora de los raleados contingentes de Falange en ocasión de las movilizaciones populares proruptura con el régimen franquista, o apelaron a la infiltración en organizaciones republicanas mediante el uso de recursos reservados (formalmente destinados al presupuesto cultural).

De hecho, el panorama del asociacionismo inmigratorio quedó congelado en las posiciones adoptadas por las entidades durante la Guerra Civil, con una mayoría abrumadora (en número de instituciones y en cobertura de afiliados) decantada hacia la fidelidad al ideal republicano. Es preciso tener presente que en esos años (los de la posguerra mundial, hasta fines de la década de los 50) el flujo inmigratorio español alcanzó otra vez carácter masivo: si bien se trató de una emigración de causalidad fundamentalmente económica, sus componentes fueron portadores de un fuerte rechazo a las modalidades represivas instauradas por el franquismo. La vitalización del asociacionismo inmigratorio (en el cauce de las instituciones preexistentes, o mediante la creación de nuevas entidades) fue una nota distintiva del período, que no resultó precisamente funcional a la política exterior española.

En el campo estrictamente político, las actividades de contestación al régimen franquista desde el seno de la inmigración fueron hegemonizadas en este período por dos entidades: Casa de España, que reunía a quienes aceptaban las orientaciones del Partido Comunista, y Centro Republicano Español, en el que confluían los adherentes a Izquierda Republicana, el Partido Socialista, Unión Republicana, galleguistas, catalanistas y cenetistas. Aludidos por la diplomacia franquista como «los rojos», más allá de las diferencias ideológicas y estratégicas que cimentaron su tenaz división institucional, estas entidades militantes lograron coordinar su acción con amplios sectores de la sociedad uruguaya, promoviendo movilizaciones de masas cuya significación no pudo ser disimulada. El fervor antifranquista de la capital uruguaya habilitó la frecuente visita de personeros republicanos (Diego Martínez Barrio, José Miaja, Alfonso Rodríguez Castelao, Luis Jiménez de Asúa, Indalecio Prieto, José Antonio de Aguirre, entre otros), recibidos como héroes de una causa cuyo triunfo se pretendía pendiente.

\section{LA ESTRATEGIA ANTE EL CAMBIO MIGRATORIO}

Hacia fines de la década de 1950, mientras la emigración española reorientó sus destinos (Francia, Alemania, Bélgica) y el Plan de Estabilización insi- 
nuó un saneamiento de la economía española (agotado el modelo autárquico), las condiciones económicas y sociales de Uruguay sufrieron un viraje sustancial. La crisis avanzó a ritmo sostenido, resultando inútiles para contenerla los intentos desarrollistas inspirados por la CEPAL. Si bien la liberalización de la economía española y la implementación de los Planes de Desarrollo no alcanzaron la plenitud de logros proclamada oficialmente, el mejoramiento de la situación se hizo sentir, aunque todavía resultara sustentado en buena medida en las remesas de los obreros españoles afincados en la Europa industrializada. De hecho, en los primeros años de la década de 1960 el agotamiento de la corriente inmigratoria española en Uruguay se hizo inocultable: en 1962 se registró el último saldo migratorio favorable para el país de arribada. Desde entonces, primero por goteo y más tarde en volúmenes muy significativos, se produjo un retorno de españoles a su tierra de origen, que disminuyó el peso de la colectividad inmigrada en Uruguay.

Las consecuencias del fenómeno no tardaron en hacerse sentir en el panorama del asociacionismo: instituciones debilitadas por el descenso de su caudal de afiliados terminaron por disponer la clausura de sus actividades, cuando no agonizaron transformadas en meros rótulos (usufructuados por autoridades que carecían de la legitimación derivada de renovaciones regulares). Existió lo que bien puede denominarse un asociacionismo dormido. Sobre ese tejido debilitado actuó, entonces, la política exterior del régimen, mediante un nuevo plan de cooptación. Para evaluar las posibilidades de éxito que semejante estrategia tenía, es preciso advertir que la crisis económica y social uruguaya resultó acompañada de un deterioro de la institucionalidad democrática, que culminaría en la instauración de un régimen dictatorial en 1973. El clima político tradicional de la sociedad uruguaya se ensombreció, y en ese caldo de cultivo de intemperancias y regresiones, los elementos franquistas de la colectividad lograron finalmente prosperar en sus propósitos, al amparo de solidaridades con el autoritarismo naciente ${ }^{28}$.

Ya en 1962, durante el II Congreso de la Emigración Española, el doctor José María del Rey presentó un «esquema para una política hispánica en el Río de la Plata», que reconocía a los «centros culturales y sociales de la colo-

28 Un caso paradigmático, a estos efectos, fue el del gallego Filiberto Ginzo Gil, escribano de profesión, que acompañó tempranamente la estrategia de cooptación del asociacionismo inmigratorio desplegada por la Embajada franquista, presidió el Club Español en 1972-1973, y mantuvo notoria cercanía al régimen dictatorial uruguayo, desempeñándose como subsecretario de Relaciones Exteriores (interinó la Cancillería entre setiembre y noviembre de 1981, y entre abril y mayo de 1982) y a partir de marzo de 1984 (bajo la presidencia del teniente general Gregorio Álvarez) como ministro de Industria y Energía. 
nia española» como una de las piezas fundamentales («o maestras») para «el restablecimiento de la unidad perdida» entre la antigua metrópoli y la América hispana. La valoración del asociacionismo inmigratorio que efectuó Del Rey no pudo disimular cierto desdén intelectual: «hacen [los centros de inmigrantes] todo lo que pueden, todo lo que son capaces de realizar. Podrá no ser mucho, pero más no pueden hacer. No existe ningún derecho para exigirles más». Y enseguida diseñó el plan tutorial que era preciso implementar: «Pero cuánto más, sobre todo cuánto de mayor alcance y trascendencia podrían realizar si estuvieran bien asistidos y orientados. [...] En estas colonias españolas de ultramar puede tener la Patria [...] las más fieles colaboradoras para una política cultural hispánica. Pero necesitan ser asistidas, aconsejadas, guiadas, sostenidas» ${ }^{29}$. Esa noción de minusvalía atribuida al asociacionismo inmigratorio autogestionado, que exigía concurrir al rescate del instrumento asignándole funciones y modalidades de actuación, a la par que requiriéndole disciplina, se compadeció con las necesidades de una estrategia que no dejaba de responder a las viejas obsesiones del franquismo: «Se ha dicho que Montevideo es la sede americana del comunismo internacional. Se le ha llamado también al Uruguay, [...] «los estados pontificios de la masonería». [...] Pues bien, ¿por qué no ha de ser Montevideo la sede americana de la política cultural hispánica o, cuando menos, para el Río de la Plata?» ${ }^{30}$.

En esa línea de pensamiento, los voceros de las asociaciones «adictas»al régimen aprovecharon las instancias de los Congresos de la Emigración Española a Ultramar para asumir personería por sus coterráneos inmigrados en Uruguay y avanzar en la estrategia de cooptación a cargo de la representación diplomática. En octubre de 1965 la Institución Cultural Española del Uruguay consignaba en su ponencia al III Congreso: «Pensamos que una Embajada debiera contar con un funcionario especializado para tratar con la colectividad española en cuanto tal, atender sus sugerencias, dar curso a sus necesidades y aspiraciones, coordinar sus esfuerzos, dirigirla y orientarla, y elevar a la superioridad aquellos proyectos para los que se solicita o se pretende un apoyo económico estatal» ${ }^{31}$. La idea de cómo era posible allegar fidelidades a partir de atender necesidades económicas, no dejó de mencionarse públicamente sin pudor alguno, más aún significándola como garantía de una estrategia inteligente: «Otra gran realidad, ha sido la obra benéfica que han realizado las autoridades españolas, a través del Ministerio de Trabajo, con donaciones de im-

29 Del Rey, 1962: 130-131.

30 Idem: 132.

31 Transcripto en Hispanidad. Revista Oficial de la Federación de Instituciones Españolas del Uruguyay, 1 (Montevideo, 1970): 57. 
portancia, que ha[n] asombrado, y que los descreídos de otrora son los propagandistas de ahora [sic] $\rangle^{32}$. El encargado de llevar a cabo semejante labor, en la década de los 60, fue el ministro encargado de los Asuntos Consulares de la Embajada de España, José Luis Ochoa, quien en declaraciones a «El Diario Español» de Montevideo sintetizó los «logros» de su accionar: «Para las Instituciones Españolas hemos pedido como Uds. "buscaban", el apoyo y la colaboración del Gobierno. No citaré cifras, aunque éstas han sido importantes. No se trata de un Debe y Haber entre España y los españoles del Uruguay. Se ha ayudado económicamente con todo lo que el Estado español podía y, sin duda alguna, con menos de lo que a Instituciones de las que España se siente legítimamente orgullosa se debía» ${ }^{33}$.

En paralelo con esta asistencia del gobierno español a las instituciones de la colectividad, y con el protagonismo indiscutible del doctor José María del Rey (quien desde 1936 había acompañado todas las acciones de la representación diplomática franquista), en agosto de 1967 se constituyó la Federación de Instituciones Españolas en el Uruguay, como institución que expresara la «unidad» de las entidades que la componían y, en particular, su característica común: «su amor a España». La Federación se propuso «representar en los asuntos de carácter general a las instituciones españolas federadas ante las autoridades españolas, uruguayas y cualquier organismo público o privado» y «coordinar la actuación general de las instituciones federadas, respetando la autonomía de cada una de ellas», así como «mantener la concordia y estimular la mutua ayuda entre las mismas ${ }^{34}$. Participaron del emprendimiento entidades del tramado asociativo tradicional (Casa de Asturias, Casa de Galicia, Centro Asturiano, Centro Gallego, Centro Orensano, Centro Pontevedrés, Centro Valle Miñor, Club Español, Sociedad Islas Canarias) que en muchos casos debieron vencer resistencias internas para federarse; instituciones que representaban los intereses económicos de la élite inmigratoria o sus canales de penetración social (Cámara Española de Comercio, Institución Cultural Española, Hospital Español, Hogar Español de Ancianos); sociedades de padrón social muy reducido (Centro Alma Gallega, Centro Arnoya, Centro Montañés, Centro Ortegano, Centro San Miguel de Oya, Círculo Balear, Hijos de Galicia, Hijos del Puerto del Son, Peña Andaluza, Unión Hijos de Morgadanes); y, por fin, entidades virtuales (Agrupación Gallega, Liga Española de

32 Comentarios a cargo del Esc. Filiberto Ginzo Gil sobre las conclusiones del 2. ${ }^{\circ}$ Congreso de la Emigración Española a Ultramar, en Hispanidad, 1 (Montevideo, 1970): 37.

33 EL Diario Español (Montevideo, 18 de mayo de 1968).

34 Acta de constitución de la Federación de Instituciones Españolas en el Uruguay, publicada en Hispanidad, 1 (Montevideo, 1970): 5. 
Deportes, Peña Taurina, Tradición Española). Las instituciones del Interior del país, también adheridas, eran nominativamente españolas (tal el caso de las Sociedades Españolas de Socorros Mutuos de Mercedes, Paysandú y Melo, todas ellas en realidad entidades de asistencia médica locales sin nexos efectivos con la inmigración peninsular), o constituían nucleamientos de creación ad hoc para los fines publicitarios de una amplia cobertura federativa.

Con la puesta en marcha de la Federación se pretendió disciplinar al asociacionismo inmigratorio, poniéndolo bajo la orientación de la representación diplomática española en Uruguay, al tiempo que deslegitimar la acción de las entidades de prédica antifranquista (Casal Català, Centro Republicano Español, Euskal Erría, Patronato da Cultura Galega). El mensaje que el presidente de la Federación, José María del Rey, dirigió a la colectividad el 12 de octubre de 1970, dejó bien definida esa intencionalidad, marcando los límites que se reconocían a la proclamada «autonomía» de las instituciones federadas (a las que se les trazaba una ruta inalterable): «Lo único que se reclama de unas y otras instituciones es su voluntad de permanecer fieles a España en el amor y en el servicio. [...] con [...] respeto y lealtad deberemos prestar nuestra colaboración a las autoridades diplomáticas y consulares del Estado español, que son los verdaderos representantes de nuestra patria en el Uruguay. Colaborando lealmente con ellas, estamos en realidad sirviendo a España misma. [...] una Federación que se propusiese actual o al margen de las autoridades españolas o al margen del Instituto Español de Emigración, perdería mucho, si no todo, de su significación y sentido, y desde luego casi totalmente su eficacia» ${ }^{35}$.

Más allá del operativo publicitario que la Federación supuso (dar la sensación de que la abrumadora mayoría de la colectividad española reconocía finalmente al régimen), hubo en la implementación de la estrategia que lo hizo posible un «cobro de viejas cuentas» que los personeros locales de Falange sintieron como triunfo propio, como el fruto de su tenacidad proselitista (de su «lealtad», dirían retóricamente). Nada se disimuló, por cierto. El órgano de prensa de la Federación (del cual sólo apareció un número), denominado Hispanidad, mantuvo sinonimia con el vocero de la prédica franquista que entre 1939 y 1942 (y bajo el rótulo de «Órgano Oficial de la FET y de las JONS en el Uruguay») dirigiera en Montevideo el jefe provincial de aquélla, Germán Fernández Fraga. El presidente de la Federación aprovechó la festividad uruguaya del 18 de julio (aniversario de la jura de la primera Constitución) de 1970, para conmemorar el alzamiento; en mensaje dirigido a sus coterráneos, afirmó entonces: «No deja de ser una feliz coincidencia el hecho de que uru-

35 Transcripto en Del Rey, 1975: 7-12. 
guayos y españoles celebremos en este mismo día, 18 de Julio, nuestras respectivas fiestas patrias. [...] Yo formulo los más sinceros y cordiales votos para que cada nuevo 18 de julio, que no es otra cosa sino la fiesta de la unidad española, de la hermandad española, del reencuentro de la España eterna consigo misma en lo esencial y permanente, nos encuentre a los españoles de América cada vez más fuertemente unidos [...] y en cordial colaboración con las autoridades diplomáticas y consulares del Estado Español [...] $\gg^{36}$. En similar tesitura, otro ex jefe provincial de Falange en Uruguay, Ángel Aller, partícipe con Del Rey y Fernández Fraga del «operativo Federación» y compañeros de andanzas proselitistas desde 1936, escribió con motivo del Día de la Hispanidad de 1970, un artículo titulado «Unidad», en el que retomó viejos tópicos de la retórica falangista (la España una y su vocación imperial), en la ocasión remozados al gusto de la guerra fría, con alusión escasamente sutil a la condición del centinela de Occidente: «La múltiple riqueza de paisajes y tónicas representa en España otras tantas maneras de vivir. [...] No debemos, en cambio, usarla como desintegradora de la totalidad fundamental. Sin que ninguno de nosotros renuncie a lo más íntimo y propio de su ser, es necesario que nos aproximemos y entendamos en el amor a una patria cuyo nombre abarca todos los extremos: España. Otorguémosle un valor de fusión ideal. España tuvo - tendrá siempre - un inmenso quehacer en el mundo. Si el ser europeo significa ser apto para la historia occidental, España supo mostrar esa aptitud de modo eminentísimo. Ninguna región nuestra, por sí sola, hubiera dado cima a tal proeza» ${ }^{37}$.

Para que no quedara duda de la línea que era preciso cimentar en el seno de la colectividad de inmigrantes españoles, ya en 1969 el consejero cultural de la Embajada, Tomás Lozano, decidió clausurar el curso de conferencias organizado por el Instituto Uruguayo de Cultura Hispánica y el Círculo Cultural Femenino Hispanouruguayo (otra de las entidades fantasmas del nuevo tramado

36 Transcripto en Del Rey, 1975: 13 y 15.

37 Hispanidad, 1 (Montevideo, 1970): 33.

38 Puestos a generar expectativas de apoyo masivo a su estrategia, los articuladores del «operativo Federación» no demostraron cautela a la hora de «crear» instituciones o conferirle a pequeños grupos, socialmente insignificantes, estatuto de asociacionismo inmigratorio. Así sucedió con la denominada Federación de Entidades Católicas Españolas en Montevideo (FECE), que nucleó a la Sociedad Española de la Virgen del Pilar y del Apóstol Santiago, la Sociedad Femenina Altas Miras Isabel la Católica, la Congregación de Nuestra Señora de Covadonga, la Congregación de Nuestra Señora de los Desamparados, la Agrupación Montserratina de Montevideo, la Cofradía del Apóstol Santiago (de la iglesia de Nuestra Señora del Carmen, de la Aguada) y la Cofradía del Apóstol Santiago (de la iglesia Parroquial de San Pedro). 
societario generado en torno a la Federación ${ }^{38}$ ), abordando el tema «Ramiro de Maeztu, humanista de la Hispanidad».

Los logros de la Federación fueron (probablemente, no se pretendió que alcanzaran otra dimensión) básicamente publicitarios ${ }^{39}$. Ante los múltiples problemas que el tiempo epilogal del franquismo enfrentaba, se puso énfasis en la unidad de la colonia inmigrante «junto» a la España oficial. A ese fin sirvió tanto la elección de la «Maja Iberia» como la difusión de los NO-DO, el otorgamiento de becas a graduados universitarios como la asistencia financiera directa a instituciones mutuales de asistencia médica nacidas en el seno del colectivo inmigrado, la retórica celebratoria de los 18 de julio o del Día de la Hispanidad como las invocaciones a la lealtad con la que los inmigrantes debían posicionarse ante el gobierno uruguayo (por cierto, desde 1967 en camino irreversible de deterioro democrático, que culminaría con el golpe de Estado del Presidente Bordaberry en 1973). Pero quizás la acción paradigmática fue la de la denominada «Operación España»: varias decenas de inmigrantes que no habían visitado su tierra desde que arribaran al Uruguay, fueron llevados (en septiembre de 1969) por el Instituto Español de Emigración en viaje gratuito a la Península, con itinerario pautado, que incluyó una audiencia del Caudillo en el Palacio Real de Madrid. A unos emocionados y utilizados «retornantes circunstanciales», el Jefe del Estado les recordó, con apelación a uno de sus tópicos recurrentes: «Una de las preocupaciones de mi vida política, ha sido el devolver a los españoles el orgullo de serlo».

\section{CODA}

El azaroso tránsito de la política exterior del franquismo para transformar a la emigración ultramarina en «telón de fondo» de sus puestas en la escena internacional, alcanzó muy tardíamente su objetivo de disciplinamiento del asociacionismo español en Uruguay. De hecho, los frutos que pudo obtener fueron magros, no sólo porque la sociedad uruguaya (y los inmigrantes que a ella se habían integrado) se hallaba ya inmersa en graves problemas de viabilidad

39 Este mismo carácter tuvo un planteo del inmigrante gallego (y empresario) Rafael Castro Marrozos, en el sentido de construir en el centro de Montevideo el «Palacio España», un edificio de varias plantas que incluyera todas las actividades societarias de la colectividad (algo así como una superestructura edilicia que «mostrara la unidad»). La iniciativa era sólo publicitaria, pues la realidad del colectivo inmigrante hacía imposible un emprendimiento de tal naturaleza, y aunque su impulsor afirmara que «los recursos si los sabemos buscar existen» (seguramente pensando en la «bolsa abierta» del gobierno peninsular), no promovió instancias ciertas de compromiso con su idea. Hispanidad, 1 (Montevideo, 1970): 101). 
económica y convivencia pacífica, sino porque el panorama peninsular se transformaba rápidamente, en una pluralidad de direcciones que, al acentuar la contestación al autoritarismo gubernamental, instaló visiblemente la agonía del régimen. De allí que lo que hubiera podido confluir con los intereses de Madrid en las décadas de los 40 o los 50, resultara disfuncional a fines de los 60 y en las vísperas de la muerte del Caudillo. La victoria «a lo Pirro» de los tenaces militantes falangistas de tres décadas atrás, al embridar a las dirigencias del asociacionismo inmigratorio, envuelta como fue en retóricas manifestaciones de lealtad a la España una, tuvo más de sainete que de drama. La transición democrática en España coincidió con la agudización de la dictadura en Uruguay, por lo que la Federación de Instituciones Españolas no pudo evitar la desaparición de varias de sus entidades afiliadas, arrastradas por la crisis socioeconómica y la inestabilidad institucional del país. En todo caso, sus actividades resultaron (por anacrónicas) disfuncionales al proceso que tenía lugar en la Península, y terminaron por favorecer tan sólo los planes personales de algunos partiquinos de la situación de facto en Uruguay.

\section{BIBLIOGRAFÍA}

Del Rey, José María, Presencia. Testimonio. Compromiso (Ensayos), Montevideo, Publicaciones del Instituto Uruguayo de Cultura Hispánica, 1962.

Del Rey, José María, En torno a los problemas de la colectividad española en el Uruguay (Selección de artículos), Montevideo, 1975.

Faraone, Roque, Blanca París y Juan Oddone, Cronología comparada de la Historia del Uruguay. 1830-1985, Montevideo, Universidad de la República, 1997.

Oddone, Juan, Uruguay entre la Depresión y la Guerra. 1929-1945, Montevideo, Fundación de Cultura Universitaria, 1990.

Registro Nacional de Leyes y Decretos de la República Oriental del Uruguay. Año 1940, Montevideo, 1941.

Registro Nacional de Leyes y Decretos de la República Oriental del Uruguay. Año 1942, Montevideo, 1943.

Zubillaga, Carlos, Hacer la América. Estudios históricos sobre la inmigración española al Uruguay, Montevideo, Editorial Fin de Siglo, 1993.

Zubillaga, Carlos, La Utopía cosmopolita. Tres perspectivas históricas de la inmigración masiva en Uruguay, Montevideo, Facultad de Humanidades y Ciencias de la Educación, 1998. 


\section{SPANISH MIGRATORY ASSOCIATIONISM IN URUGUAY WITHIN THE FRANCO PERIOD: BETWEEN OPPOSITION AND DISCIPLINE}

This paper analyses the emergence of Spanish associationism in Uruguay and the evolution of its relations with the peninsular government, specially within the context of the civil war and the Franco regime. The information yielded by the Spanish diplomatic representation in Montevideo is complemented with the "hispanist» discourse in books and journals published within the immigrated community, tending to the setting-up of political and ideological discipline structures.

KEY WORDS: Immigration, associationism, Uruguay, Franco period/regime, diplomacy, 20th century. 